\title{
Evaluation of potential organ culture media for eye banking using human donor corneas
}

\author{
T Møller-Pedersen, U Hartmann, H J Møller, N Ehlers, K Engelmann
}

Department of Ophthalmology, Århus University Hospital, 8000 Århus C,

Denmark

T Møller-Pedersen N Ehlers

Augenklinik der Medizinischen

Hochschule Hannover, Carl-Neuberg-Strasse

1, D-30625 Hannover,

Germany

U Hartmann

Department of Clinical Biochemistry, Arhus University Hospital, 8000 Århus C,

Denmark

H J Møller

Universitäts-

Augenklinik Hamburg, Martinistrasse 52, D-20246 Hamburg, Germany

K Engelmann

Correspondence to: Torben Møller-Pedersen, $\mathrm{MD}, \mathrm{PhD}$, Department of Ophthalmology, Århus University Hospital, DK-8000 Århus C, Denmark tmp@dadlnet.dk

Accepted for publication 27 March 2001

\begin{abstract}
Aim-To evaluate the ability of different commercially available cell culture solutions to preserve human donor corneas during 3 weeks of "closed system" organ culture at physiological temperature. This screening was performed in an attempt to establish a rational basis for the development of a serum-free organ culture medium for eye banking.
\end{abstract}

Methods-72 normal human donor corneas were organ cultured for 21 days at $31^{\circ} \mathrm{C}$ in eight different test media (nine corneas in each group). The basic culture solutions included: minimal essential medium (MEM), MEM with stabilised L-glutamine, M199, DIF-1000, SFM, F99, and F99 with ascorbic acid, insulin, bFGF, transferrin, selenium, and lipids (termed F99-Sr). All media were supplemented with $2 \%$ fetal calf serum (FCS), except for MEM, which was also studied at $8 \%$ FCS. The evaluation parameters included: (1) the endothelial cell loss as evaluated using trypan blue staining; (2) the ability of keratocytes and endothelial cells to incorporate tritiated uridine into RNA as evaluated using autoradiography and digital image analysis; (3) the leakage of immunogenic keratan sulphate as assessed using ELISA; and (4) changes in storage medium $\mathrm{pH}$, glucose, and lactate content.

Results-SFM induced the lowest endothelial cell loss of $14 \%$ (SD $2 \%$ ) and the highest RNA synthesis rates of all test solutions supplemented with $2 \%$ FCS. Corneas stored in SFM also showed the least leakage of keratan sulphate and the highest glucose consumption and lactate production. In five media (MEM with $2 \%$ FCS, MEM with stabilised L-glutamine, M199, F99, and F99-Sr), comparable and intermediate potentials for organ culture were observed with endothelial cell loss of $16-19 \%$. By contrast, $29 \%(4 \%)$ of the endothelium was lost after storage in DIF1000. Interestingly, the use of $8 \%$ FCS (in MEM) had a marked protective effect on the endothelium, which showed the highest RNA synthetic activity combined with a cell loss of only $11 \%(4 \%)$, compared with $19 \%(6 \%)$ at $2 \%$ FCS $(\mathrm{p}<0.05)$.

Conclusion-Among the present test solutions, SFM appears to be the most prominent candidate for a new corneal organ culture medium and should be further tested and possibly refined to effectively substitute serum addition.

(Br f Ophthalmol 2001;85:1075-1079)
More than 14000 human donor corneas are processed annually in the European eye banks. ${ }^{1}$ Organ culture is the preferred storage method, in which the cornea can be kept at $31-37^{\circ} \mathrm{C}$ for a current maximum of 7 weeks and grafted successfully afterwards. ${ }^{1-4}$ During the organ culture period, the donor tissue undergoes screening for microbial contamination and positive serology (hepatitis, HIV, etc) as well as optional HLA typing and matching. ${ }^{1}$ The current preservation media generally consist of a basic culture solution, usually minimal essential medium (MEM), supplemented with varying amounts of fetal calf serum (FCS) ranging from $2 \%$ to $10 \% .{ }^{1}$ Currently, this FCS enrichment is mandatory because of a lack of many essential (and unidentified) components in the basic culture media. Unfortunately, there is an unpredictable variation in the ingredients and composition of different FCS batches, which appears to be closely related to variation in the postoperative graft quality and performance. ${ }^{56}$ Furthermore, there is a potential risk of transferable diseases and other unwanted side effects from unknown hazardous components in bovine serum. It is therefore desirable for the European eye banks to search for more standardised and optimised organ culture conditions using well characterised and serum free preservation media.

For these reasons, we have initiated experimental studies to evaluate systematically the impact of a wide range of commercially available basic culture solutions (which may work as starting points for subsequent refinements). Based on the ability to induce proliferation and morphological changes in primary cultures of human corneal endothelial cells (HCEC), we have recently performed an initial evaluation and comparison of 11 different cell culture media supplemented with varying concentrations of FCS ranging from $0 \%$ to $10 \%{ }^{7}$ Since this HCEC growth assay may not be a fully relevant screening model for the entire cornea, it is important to perform additional analyses of the storage media quality using intact donor tissue. Therefore in the present study, a total of 72 normal human donor corneas were obtained post mortem and organ cultured for 21 days in eight different test solutions. This paper summarises our evaluation of these media using quantitative viability parameters.

\section{Materials and methods}

ORGAN CULTURE TECHNIQUE

A total of 72 human donor eyes (all without known corneal disease) were obtained post mortem from the cornea banks of Århus, Denmark and Hamburg, Germany. Mean donor 
Table 1 Specifications of the eight test media

\begin{tabular}{|c|c|c|c|}
\hline Name & Basic component & $\begin{array}{l}\% \text { Serum } \\
\text { supplementation }\end{array}$ & Comments \\
\hline MEM- $8 \%$ & MEM-Earle (Seromed) & 8 & $\begin{array}{l}\text { Commonly used for organ culture in European eye } \\
\text { banks }^{1}\end{array}$ \\
\hline MEM-2\% & MEM-Earle (Seromed) & 2 & $\begin{array}{l}\text { Commonly used for organ culture in European eye } \\
\text { banks }^{1}\end{array}$ \\
\hline MEM-G & MEM-Earle (Seromed) & 2 & $\begin{array}{l}\text { MEM supplemented with } 2 \mathrm{mM} \text { L-analyl-L-glutamine, } \\
\text { a stabilised form (dipeptide) of the amino acid } \\
\text { L-glutamine }\end{array}$ \\
\hline F99 & M199 + Ham's F12 (1:1) (Gibco) & 2 & Used for corneal endothelial cell growth ${ }^{14}$ \\
\hline F99-Sr & M199 + Ham's F12 (1:1) (Gibco) & 2 & $\begin{array}{l}\text { F99 supplemented with ascorbic acid, insulin, bFGF, } \\
\text { transferrin, selenium, and lipids }{ }^{14}\end{array}$ \\
\hline M199 & M199-Earle (Seromed) & 2 & $\begin{array}{l}\text { Intended for short term corneal preservation at } 4^{\circ} \mathrm{C} \\
\text { (cold storage for up to } 10 \text { days) }\end{array}$ \\
\hline SFM & Company formula (Gibco) & 2 & $\begin{array}{l}\text { Developed for serum free growth of vascular } \\
\text { endothelial cells }\end{array}$ \\
\hline DIF-1000 & Company formula (Seromed) & 2 & Initially used for serum free growth of hybridoma cells \\
\hline
\end{tabular}

See company information sheets for further details on the specific composition of each medium.

age was 68 (SD 13) years (range 24-89) and the mean postmortem time was 39 (13) hours (range 23-72) (defined as the interval between death and incubation of the cornea). All corneas included in this study fulfilled the standards of the European Eye Bank Association for donor material used for grafting. ${ }^{1}$ The eyes were rinsed under tap water and the corneas were carefully excised including a 2 mm scleral rim. ${ }^{8}$ The corneas were randomly divided into eight experimental groups (with nine corneas each) and incubated at $31^{\circ} \mathrm{C}$ for 21 days (hanging in a suture through the scleral rim) in $70 \mathrm{ml}$ airtight glass bottles containing $20 \mathrm{ml}$ atmospheric air and $50 \mathrm{ml}$ of one of the eight test media (Table 1). These media were selected following an initial evaluation using primary cultures of HCEC as recently reported. ${ }^{7}$ Different supplements were added to ensure that all storage solutions contained: $12.5 \mathrm{mM}$ HEPES, $2.0 \mathrm{mg} / \mathrm{ml}$ gentamicin, and (in seven of the eight media) $2 \mathrm{mM}$ of the amino acid L-glutamine that is known to be unstable in solution. Therefore, one group of corneas (termed MEM-G) received $2 \mathrm{mM}$ L-analyl-L-glutamine (Table 1), which is a stabilised form (dipeptide) of L-glutamine. Furthermore, 2\% FCS (batch B:425C, Seromed) was added to seven of the eight test groups, whereas one group of corneas (termed MEM- $8 \%$ ) received $8 \%$ FCS supplementation (Table 1). Finally, pH was adjusted to 7.4 in all culture media using $\mathrm{NaHCO}_{3}$. To maintain sterility, the media were not changed during the 21 day "closed system" organ culture.

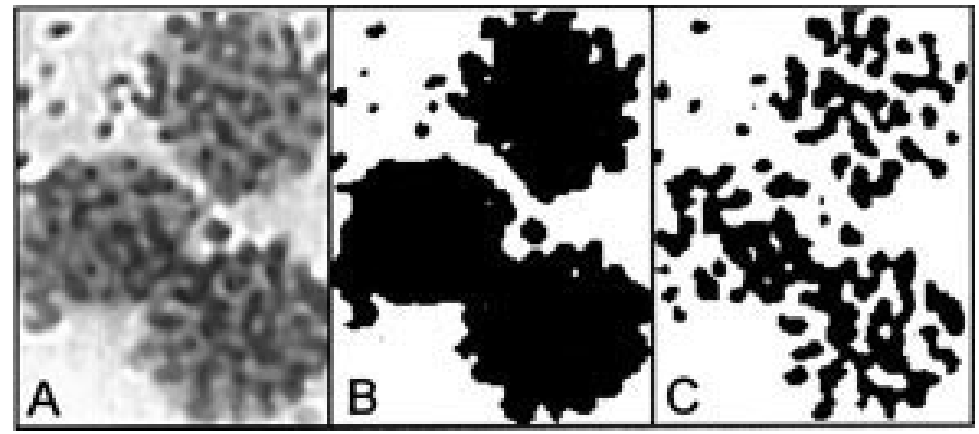

Figure 1 Autoradiograph of human donor endothelial cells following 48 hours of ${ }^{3}$ H-uridine incorporation during corneal organ culture. (A) Dense accumulations of silver grains cover three radiolabelled nuclei undergoing $R N A$ synthesis (haematoxylin and eosin counterstain). Profiles of the same nuclei (B) and the area of the autoradiographic silver grains covering these profiles $(C)$ as assessed by digital image analysis.
ASSESSMENT OF ENDOTHELIAL CELL DENSITY Immediately before and after incubation, the endothelial cell density of each donor cornea was estimated using trypan blue staining and osmotically induced dilatation of the intercellular spaces by $0.9 \% \mathrm{NaCl}^{8}{ }^{8}$ The difference between the two counts represents the cell loss during the storage period.

\section{ESTIMATION OF RNA SYNTHESIS}

To radiolabel the RNA synthesis, $1.0 \mu \mathrm{Ci} / \mathrm{ml}$ 5,6- ${ }^{3} \mathrm{H}$-uridine (specific activity $38.5 \mathrm{Ci} / \mathrm{mmol}$, NEN Research Products) was added to each bottle 48 hours before termination of the incubation as described previously. ${ }^{9}$ At day 21 , central pieces of the corneal endothelium including Descemet's membrane were gently peeled off, mounted on gelatinised slides, fixed in formalin, air dried, and prepared for autoradiography. Similarly, samples of the central stroma were fixed in formalin and processed for histology and autoradiography. Using the same batch of reagents, all slides were assayed in parallel, including appropriate control sections from corneas incubated without radioactivity. ${ }^{9}$ Following photographic development (at $4^{\circ} \mathrm{C}$ for 11 days) and a haematoxylin and eosin counterstain, 30 nuclear profiles of keratocytes and endothelial cells, respectively, were randomly selected and digitised for each cornea (Fig 1A). In all images, the area of the nuclear profiles (Fig 1B) and the area of autoradiographic silver grains covering the profiles (Fig 1C) were calculated using the same automated algorithms from the software package Matrox Inspector Version 1.5. ${ }^{9}$ For each cornea, the percentage of silver grains on the nuclear area represents a quantitative measure of the RNA synthesis rate that can be used as a simple estimate of cell viability. ${ }^{9}$ Obviously, the doseresponse relation for this assay may not be fully linear because of saturation of the photographic emulsion.

\section{IMMUNOGENIC KERATAN SULPHATE}

Before and after incubation, all storage media were assayed for their content of immunogenic keratan sulphate (KS) using the monoclonal antibody 5D4 (from ICN, code no 69-625-2) in a sensitive, competitive ELISA. ${ }^{10}{ }^{11}$ This 
Table 2 Characteristics of human donor corneas following 21 days of organ culture in eight different storage media

\begin{tabular}{|c|c|c|c|c|}
\hline Test medium & $\begin{array}{l}\text { Endothelial } \\
\text { cell loss (\%) }\end{array}$ & $\begin{array}{l}\text { Endothelial cell RNA synthesis } \\
\text { (\% silver grains per nuclear } \\
\text { area) }\end{array}$ & $\begin{array}{l}\text { Keratocyte RNA synthesis (\% } \\
\text { silver grains per nuclear area) }\end{array}$ & $\begin{array}{l}\text { Keratan } \\
\text { sulphate loss } \\
(\mu g / m l)\end{array}$ \\
\hline MEM-8\% & $11(4) a$ & $57(12) \mathrm{g}$ & $38(10) \mathrm{m}$ & $74(41) \mathrm{u}$ \\
\hline MEM- $2 \%$ & $19(6) b$ & $29(11)$ & $35(10) \mathrm{n}$ & $127(63)$ \\
\hline MEM-G & $17(4) \mathrm{c}$ & $37(10) \mathrm{h}$ & $34(9)$ o & $118(63)$ \\
\hline F99 & $17(4) \mathrm{d}$ & $21(7) \mathrm{i}$ & $22(8) \mathrm{p}$ & $144(60) \mathrm{v}$ \\
\hline F99-Sr & $17(3) \mathrm{e}$ & $19(11) \mathrm{j}$ & $29(11) \mathrm{q}$ & $132(34)$ \\
\hline M199 & $16(4)$ & $27(10)$ & $21(7) \mathrm{r}$ & $77(28) \mathrm{x}$ \\
\hline SFM & $14(2)$ & $48(8) \mathrm{k}$ & $42(8) \mathrm{s}$ & $57(24) \mathrm{y}$ \\
\hline DIF-1000 & 29 (4)f & $4(5) 1$ & $15(5) \mathrm{t}$ & $139(40) \mathrm{z}$ \\
\hline
\end{tabular}

Data are mean $(\mathrm{SD}), \mathrm{n}=9$.

One way analysis of variance and Student-Newman-Keuls method for all pairwise comparisons (within each column) revealed the

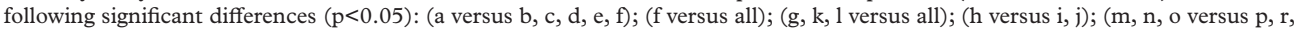
$\mathrm{t})$; (q versus $\mathrm{t}$ )( $\mathrm{s}$ versus $\mathrm{p}, \mathrm{q}, \mathrm{r}, \mathrm{t})$; (y versus all except $\mathrm{u}, \mathrm{x})$; ( $\mathrm{u}$ versus v); (x versus $\mathrm{v}, \mathrm{z}$ ).

5D4 antibody recognises an epitope on the sulphated polysaccharide structure of KS proteoglycan and has previously been used to detect KS in the cornea and other tissues..$^{9-11}$ The difference between the two measurements represents the leakage of stromal KS during the storage period and is expressed in $\mu \mathrm{g} / \mathrm{ml}$ medium. ${ }^{10} 11$

METABOLIC PARAMETERS

Before incubation and at day 21 , duplicate samples of all culture media were obtained for measurements of glucose, lactate, and $\mathrm{pH}$ as previously reported. ${ }^{9}$

STATISTICS

Data are given as mean (SD). Using SIGMASTAT Version 2.0 (Jandel Corporation, CA, USA), differences in the mean values among the groups were compared by one way analysis of variance and Student-Newman-Keuls method for all pairwise comparisons. The tendency of variables to increase or decrease together was evaluated using Pearson product moment correlation.

\section{Results}

LOSS OF ENDOTHELIAL CELLS

Before incubation, the average endothelial cell density for all 72 corneas was 2801 (327) cell/ $\mathrm{mm}^{2}$ (range 2210-3680) with no significant differences between the groups. Following 21 days, the endothelial cell loss averaged $17.5 \%$ with considerable variation among the media. Corneas stored in MEM-8\% showed the lowest cell loss, $11 \%(4 \%)$, compared with corneas kept in MEM-2\%, 19\% (6\%) ( $p<0.05)$, demonstrating a marked protective effect of a higher serum level (Table 2). Among media with $2 \%$ FCS supplementation, SFM showed the lowest cell loss, $14 \%(2 \%)$, whereas the highest cell loss, $29 \%$ (4\%), was observed in DIF-1000.

KERATOCYTE AND ENDOTHELIAL CELL RNA SYNTHESIS

After 21 days, a significant correlation $(r=$ $0.70, \mathrm{p}<0.05)$ was found between the RNA synthesis rates (degree of autoradiographic silver grain staining) of keratocytes and endothelial cells; indicating that the two cell types have parallel protein synthesising activities during storage. However, profound variation was observed among the test media. The highest level of silver grain staining $(38-57 \%)$ was found in MEM-8\% and in SFM, followed by MEM-2\% and MEM-G (29-37\%) (Table 2). An intermediate silver grain staining of 19$29 \%$ was seen in F99, F99-Sr, and M199, whereas DIF-1000 revealed the lowest RNA synthetic activity (4-15\% silver grains) with many unlabelled cells (Table 2). For both keratocytes and endothelial cells, the degree of staining was found to be inversely correlated with the loss of endothelial cells, $r=-0.63, \mathrm{p}$ $<0.05$ and $r=-0.73, \mathrm{p}<0.05$, respectively. In other words, the lower the capacity to synthesise RNA (and thereby to renew critical proteins), the higher the level of endothelial cell death.

\section{LEAKAGE OF KERATAN SULPHATE}

Before incubation, the content of $\mathrm{KS}$ was below the detection limit in all test media. After 21 days, the KS concentration in the storage media varied from 22 to $290 \mu \mathrm{g} / \mathrm{ml}$ with substantial variation among the groups. The lowest KS loss of $57(24) \mu \mathrm{g} / \mathrm{ml}$ was detected in SFM, followed by $74(41) \mu \mathrm{g} / \mathrm{ml}$ in MEM $8 \%$, and $77(28) \mu \mathrm{g} / \mathrm{ml}$ in M199 (Table 2). For the remaining five media, the average KS loss ranged from 118 to $144 \mu \mathrm{g} / \mathrm{ml}$, which corresponds to approximately $1.5 \%$ of the total content of immunogenic KS in human donor corneas. ${ }^{9}$ Interestingly, the storage medium content of KS correlated inversely with both the endothelial cell density at day $21(r=$ $-0.45, \mathrm{p}<0.05)$ and with the endothelial cell RNA synthesis rate $(r=-0.49, \mathrm{p}<0.05)$; suggesting that stromal KS leakage may depend directly on the integrity and barrier function of the endothelium as previously observed. ${ }^{12}$

METABOLIC CHANGES IN THE TEST MEDIA

In all test solutions, the initial metabolic characteristics resembled that of a physiological system with $\mathrm{pH}=7.4$, a lactate concentration ranging from 0.3 to $1.3 \mathrm{mM}$, and (in six of the eight media) a glucose concentration ranging from 5.5 to $8.0 \mathrm{mM}$. However, two media (SFM and DIF-1000) had a high initial glucose content of about $17 \mathrm{mM}$. Interestingly, corneas stored in these two media displayed a significantly $(p<0.05)$ higher glucose utilisation ( -6.9 to $-7.3 \mathrm{mM}$ ) during the 21 day incubation compared with all other test solutions $(-4.3$ to $-5.5 \mathrm{mM}$ ) (Table 3 ). This finding suggests that a general lack of glucose may limit the metabolic capacity of donor corneas kept in MEM, M199, and F99 based media. It 
Table 3 Changes in glucose, lactate, and pH of eight different test media following 21 days of human corneal organ culture at $31^{\circ} \mathrm{C}$

\begin{tabular}{lllll}
\hline Test medium & $\begin{array}{l}\Delta[\text { [glucose] } \\
(\mathrm{mM})\end{array}$ & $\begin{array}{l}\Delta \text { [lactate] } \\
(\mathrm{mM})\end{array}$ & $\begin{array}{l}\text { Glycolysis } \\
(\%)\end{array}$ & $\Delta$ pH(units) \\
\hline MEM-8\% & $-4.9(0.4)$ & $8.5(0.2)$ & $85(5)$ & $-0.64(0.14) \mathrm{e}$ \\
MEM-2\% & $-4.5(0.2)$ & $7.2(0.4)$ & $81(6)$ & $-0.39(0.10) \mathrm{f}$ \\
MEM-G & $-5.0(0.3)$ & $7.9(0.2)$ & $78(4)$ & $-0.51(0.05) \mathrm{g}$ \\
F99 & $-4.3(0.6)$ & $7.5(0.4)$ & $88(9)$ & $-0.64(0.07) \mathrm{h}$ \\
F99-Sr & $-5.5(1.4)$ & $7.8(1.4)$ & $72(11)$ & $-0.67(0.05) \mathrm{i}$ \\
M199 & $-4.8(0.5)$ & $7.5(1.0)$ & $78(10)$ & $-0.37(0.06) \mathrm{j}$ \\
SFM & $-7.3(1.9) \mathrm{a}$ & $12.4(2.0) \mathrm{c}$ & $85(10)$ & $-0.65(0.17) \mathrm{k}$ \\
DIF-1000 & $-6.9(1.9) \mathrm{b}$ & $6.9(0.6)$ & $54(11) \mathrm{d}$ & $-0.39(0.07) \mathrm{l}$ \\
\hline
\end{tabular}

Data are mean (SD), $\mathrm{n}=9$.

$\Delta=$ day 21 -day 0 .

*assuming an equivalence of one mol glucose to two mol lactate and ignoring other metabolic pathways.

One way analysis of variance and Student-Newman-Keuls method for all pairwise comparisons (within each column) revealed the following significant differences $(\mathrm{p}<0.05)$ : (a versus all except b); (b versus all except a); (c versus all); (d versus all); (e, h, i, k versus $f, g, j, 1)$; (g versus f, j, l).

should be noted that SFM showed the highest lactate production of $12.4 \mathrm{mM}$ ( $\mathrm{p}<0.05)$, whereas corneas kept in DIF-1000 revealed the lowest level of lactate formation, $6.9 \mathrm{mM}$ (Table 3). Assuming a direct equivalence of 1 $\mathrm{M}$ glucose to $2 \mathrm{M}$ lactate (and ignoring other metabolic pathways), it appears that corneas kept in SFM predominantly utilises glucose by $85 \%$ glycolysis and $15 \%$ oxidation (Table 3 ), which mimics the metabolism of a normal cornea. ${ }^{13}$ Comparable glycolytic activity (72$88 \%$ ) was observed in all other test media, except for DIF-1000 that only showed 54\% glycolysis $(\mathrm{p}<0.05)$ (Table 3$)$. It is interesting to note that the accumulation of lactate was inversely correlated with the endothelial cell loss $(r=-0.43, \mathrm{p}<0.01)$, confirming that a well functioning cornea has a high glycolytic activity. As for changes in storage medium $\mathrm{pH}$, the eight groups showed a significant variation ranging from -0.37 to -0.67 units (Table 3 ); however, no systematic impact of these $\mathrm{pH}$ changes could be identified on neither the endothelial cell loss, the RNA synthesis rates, nor the leakage of keratan sulphate.

DONOR CHARACTERISTICS

No systematic influence of neither donor age, sex, medication, cause of death, nor the post mortem time could be identified on any of the study parameters.

\section{Discussion}

The present study showed no major differences between corneas stored in MEM and F99 based media, although F99 generally contains higher levels of multiple essential nutrients and supplements. Neither did the specific enrichment of F99 with ascorbic acid, insulin, bFGF, transferrin, selenium, and lipids ${ }^{14}$ show any improvement on corneal cell density, viability, or metabolism (Tables 2 and 3; compare F99-Sr with F99). This is in contradiction to our recent study of primary cultures of HCEC, where F99-Sr revealed the highest growth promoting capacity of 11 different test media under both serum free conditions and following $2-10 \%$ FCS supplementation. ${ }^{7}$ Thus, the nutritive requirements of proliferating cells may not exactly mirror those needed for intact (quiescent) donor corneas. Consequently, the HCEC growth assay may not be a fully relevant screening model for evaluation of corneal organ culture media. It should also be noted that no major differences were observed between corneas stored in MEM and M199, except for a significantly $(\mathrm{p}<0.05)$ lower keratocyte RNA synthetic activity in M199 (Tables 2 and 3; compare MEM-2\% with M199). According to the Directory of the European Eye Bank Association, ${ }^{1}$ only one bank is currently using M199 for long term organ culture at physiological temperature; although M199 originally was developed for short term corneal preservation at $4^{\circ} \mathrm{C}$ (cold storage for up to 10 days).

The most prominent candidate for a new organ culture medium appeared to be SFM, that induced the lowest endothelial cell loss and the highest RNA synthesis rates of all test solutions supplemented with $2 \%$ FCS (Table 2). Corneas stored in SFM also showed the lowest leakage of keratan sulphate and the highest glucose utilisation and lactate production (Table 3). SFM furthermore revealed a high growth promoting capacity in our recent screening of storage media quality using primary cultures of HCEC. ${ }^{7}$ Unfortunately, the detailed composition of SFM is currently not available from the manufacturer, although such information clearly would help to characterise the actual nutritive requirements of donor corneas kept in organ culture.

It is interesting to note that supplementation of MEM with $8 \%$ FCS had a marked protective effect on the organ cultured corneas, that showed the highest RNA synthetic activity combined with a significantly lower endothelial cell loss of only $11 \%$ (4\%), compared with $19 \%(6 \%)$ in corneas stored in MEM with $2 \%$ FCS. This is an important observation, especially since 38 out of 46 European eye banks currently are using $2 \%$ FCS supplementation for corneal organ culture, whereas eight banks are using $8-10 \%$ FCS. $^{1}$ Thus, serum obviously contributes many essential components necessary to keep the cornea viable during organ culture. An increased understanding and identification of these nutritive and regulatory survival factors is needed to limit donor endothelial cell deterioration in a serum-free medium.

Substitution of the labile amino acid L-glutamine with the stable dipeptide L-analylL-glutamine had no significant impact on the loss of endothelial cells, the RNA synthesis rates, or the leakage of keratan sulphate (Table 2; compare MEM-G with MEM-2\%). Thus, the endothelial cell loss occurred independently of the presence of labile L-glutamine in the storage media, which is consistent with a previous study of porcine corneas. ${ }^{15}$

The most viable and best preserved donor corneas generally showed a high glucose turnover with a glycolytic activity close to $85 \%$ (Table 3 ); which according to Riley ${ }^{13}$ mimics the metabolism of a normal cornea. In other words, a high lactate concentration in the storage medium appeared to be a simple marker of cell viability, that in many cases indicated a well functioning donor cornea with a low endothelial cell loss. By contrast, the observed change in storage medium $\mathrm{pH}(-0.37$ to -0.67 units $)$ 
appeared to be a poor indicator of decreased cell density and viability. Thus, a reduced extracellular $\mathrm{pH}$ did not appear to limit corneal cell viability, although it may increase the metabolic stress on the tissue. This finding is in agreement with a previous study of organ cultured cat corneas showing a normal intracellular $\mathrm{pH}$ despite an extracellular $\mathrm{pH}$ decline of 0.6 units. ${ }^{16}$

In conclusion, the majority of the tested storage media (MEM-2\%, MEM-G, M199, F99, and F99-Sr) showed comparable potentials for corneal organ culture at $2 \%$ FCS supplementation. However, there was a clear tendency for the medium SFM to maintain a higher endothelial cell density and viability at $2 \%$ FCS. Thus, SFM should be further evaluated in the absence of serum and possibly refined and optimised. In such studies, it might be beneficial not to use "closed system" organ culture but instead change the medium-for example, every week ("open system") in order to maintain corneal cell viability under long term, serum free storage. Further evaluation of SFM will be of interest.

This study was supported by the German Research Council (Deutsche Forschungsgemeinschaft; $\mathrm{Ha}$ 2484/1-1) and performed at the Danish Cornea Bank, Århus University Hospital, Denmark.

1 Pels L, Mass H, Tullo A. European eye bank association directory. 8th ed. Amsterdam: Netherlands Ophthalmic Research Institute, 2000

2 Ehlers H, Ehlers N, Hjortdal JØ. Corneal transplantation with donor tissue kept in organ culture for 7 weeks. Acta with donor tissue kept in organ cut
Ophthalmol Scand 1999;77:277-8.
3 Frueh BE, Böhnke $M$. Corneal grafting of donor tissue preserved for longer than 4 weeks in organ-culture medium. Cornea 1995;14:463-6.

4 Redbrake C, Salla S, Frantz A. Changes in human donor corneas preserved for longer than 4 weeks. Cornea 1998;17:62-5.

5 Engelmann K, Winter R. Quality control in the corneal bank-a necessary measure? Klin Monatsbl Augenheilkd 1993;203:262-8.

6 Engelmann K, Sobottka Ventura A, Drexler D, et al. A sensitive method for testing the quality of organ culture media and of individual medium components in a cornea bank. Graefes Arch Clin Exp Ophthalmol 1998;236:312-19.

7 Møller-Pedersen T, Hartmann U, Ehlers N, et al. Evaluation of potential organ culture media for eye banking using a human corneal endothelial cell growth assay. Graefes Arch Clin Exp Ophthalmol (in press).

8 Sperling S. Evaluation of the endothelium of human donor corneas by induced dilation of intercellular spaces and trypan blue. Graefes Arch Clin Exp Ophthalmol 1986;224: 428-34.

9 Møller-Pedersen T, Møller HJ. Viability of human corneal keratocytes during organ culture. Acta Ophthalmol Copenh 1996;74:449-55.

10 Møller HJ, Møller-Pedersen T, Damsgaard TE, et al. Demonstration of immunogenic keratan sulphate in commercial chondroitin 6-sulphate from shark cartilage. Implications for ELISA assays. Clin Chim Acta 1995;236:195-204.

11 Møller HJ, Larsen FS, Ingemann-Hansen T, et al. ELISA for the core protein of the cartilage large aggregating proteoglycan, aggrecan: comparison with the concentrations of immunogenic keratan sulphate in synovial fluid, serum and urine. Clin Chim Acta 1994;225:43-55.

12 Slack JW, Kangas TA, Edelhauser HF, et al. Comparison of corneal preservation media for corneal hydration and stromal proteoglycan loss. Cornea 1992;11:204-10.

13 Riley MV. Glucose and oxygen utilization by the rabbit cornea. Exp Eye Res 1969;8:193-200.

14 Engelmann K, Friedl P. Growth of human corneal endothelial cells in a serum-reduced medium. Cornea 1995;14:6270

15 Ayoubi MG, Armitage WJ, Easty DL. Corneal organ culture: effects of serum and a stabilised

16 Lass JH, Greiner JV, Meneses P, et al. $\mathrm{pH}$ of organ-culturestored corneas. Acta Ophthalmol Copenh 1988;66:538-43. 